\title{
Los Salesianos y la Amazonia ${ }^{1}$
}

Juan Bottasso Boetti

DOI: http://dx.doi.org/10.20435/tellus.v18i37.606

\section{EL CONTEXTO HISTÓRICO}

Después del remesón napoleónico que estremeció Europa, deponiendo reyes y corriendo fronteras, las grandes potencias de entonces se reunieron en Viena para restablecer el orden y volver al "ancien regime". Pero nada regresó a ser como antes.

Inglaterra exaltada por el hecho de haber derrotado al emperador francés, emprendió su ascenso definitivo como dominadora de los mares y consolidó su imperio colonial, llevándolo a la cima de su expresión y esplendor. Francia no se quedó atrás y emuló a la rival para, entre las dos, repartirse el dominio de los continente, operación que culminó con el Congreso de Berlín (1884 - 5).

No solo en esos dos países, sino en toda Europa se afirmó como definitiva la convicción que la cultura europea constituía la expresión más alta de la civilización humana y que su destino histórico no podía ser sino él de difundirla por todo el planeta.

La iglesia católica que especialmente en Francia, conoció un fuerte despertar de vitalidad, fue también contagiada por esta euforia que se tradujo en un renacer del espíritu misionero, con el epicentro en Lyon. Fue el país que conoció la fundación del mayor número de congregaciones con finalidad expresamente misionera. "Le Genie du Christianisme" de Chateaubriand supo interpretar magistralmente esta atmósfera, que veía en el auge de las misiones una estupenda realización del mandato de Jesús. "Id y enseñad"; unida a la tarea civilizadora. En este contexto fue madurando la mentalidad que más tarde se plasmó en la consigna "Evangelizar civilizando, civilizar evangelizando".

${ }^{1}$ Texto apresentado no Encontro Pan-Amazônico Salesiano - O Sínodo nos interpela! Sínodo para a Amazônia - 1 a 4 de novembro de 2018, Manaus, AM, Brasil.

${ }^{2}$ Universidade Politécnica Salesiana (UPS), Quito, Equador. Email: juanbottasso@yahoo.com 
A las manos del seminarista Juan Bosco llegó bastante de esta literatura y sembró en su conciencia el sueño misionero. Fue algo que lo acompañó toda la vida, pero por muchos años fue solamente esto: un sueño; algo un tanto nebuloso y teñido de romanticismo. Será solo después de 1870, cuando su Congregación comenzó a ser conocida y empezaron a multiplicarse las peticiones para abrir presencias en diferentes continentes, que el sueño aterrizó y tomó cuerpo.

La mayoría de los pedidos de fundación se referían a la atención a los migrantes italianos, cuya presencia asumía enormes proporciones, pero en Don Bosco permanecía la obsesión por los pueblos no evangelizados, aquellos que, además de correr el riesgo de perderse por no conocer a Cristo, vivían al margen de la "civilización": los "salvajes".

Argentina le ofreció la posibilidad de alcanzar el doble objetivo: atender a los migrantes y evangelizar a los paganos. Don Bosco tenía los ojos puestos más en los habitantes de Patagonia y Tierra de Fuego que en las barriadas de Buenos Aires, pero la realidad resultó diferente a lo que él había imaginado.

Sus salesianos pudieron entrar a Patagonia en el momento exacto en que el ejército argentino llevaba a cabo una guerra de conquista y exterminio contra los Mapuche.

El famoso sueño, en que el Santo preveía que los indios adultos se transformarían a través de los jóvenes educados por la misiones se vio trágicamente truncado.

La labor salesiana en la Patagonia siguió y fue muy fructífera, pero tomó otro rumbo.

Entonces los hijos de Don Bosco, volvieron la mirada a los indígenas amazónicos. El obispo de Cuiabá, Carlos D`Amour, pidió personalmente a Don Bosco que enviara misioneros para hacerse cargo de los indígenas y de las escuelas de la ciudad. Este pedido no pudo ser atendido por el Santo, sino por su sucesor, Don Rua.

El 12 de marzo de 1893, el mismo año en que el Vicario Apostólico de Méndez y Gualaquiza fue confiado a los salesianos para que evangelizaran a los Shuar, Monseñor Luis Lasagna fue consagrado Obispo con la responsabilidad, nada menos que la, de atender a los indios de Uruguay, Paraguay y Brasil. Se trataba de 
una tarea descomunal y casi imposible de realizar, pero aquel hombre enérgico no se amedrentó. Puso mano a la obra y regresó a América con 36 misioneros. El 18 de junio de 1894 fueron recibidos solemnemente por el pueblo y las autoridades de Cuiabá y de inmediato tomaron los contactos oportunos para dar comienzo al trabajo con los indios. Como sabemos los audaces proyectos de Mons. Lasagna fueron truncados muy pronto por su muerte trágica. No tuvo sucesor como obispo de los indios de los tres países.

Los que heredaron su compromiso fueron hombres igualmente excepcionales como Don Malán y Don Balzola. Este último en 1914 fue destinado al Rio Negro, para dar inicio al trabajo misionero en aquella región. El celo que desplegó y los viajes que realizó en un inmenso territorio tienen de lo increíble. En el registro de los bautismos de Puerto Ayacucho, Venezuela, el ultimo Vicariato entregado a los salesianos, consta que el misionero llegó hasta allá y administro el sacramento a varios indígenas.

\section{LOS SALESIANOS Y LOS INDÍGENAS}

En 1875, fecha de la primera expedición misionera salesiana, el porcentaje de los indígenas en América Latina era todavía bastante alto, antes de que las oleadas de inmigrantes hicieran variar completamente las estadísticas. En la región andina y Mesoamérica ellos aportaban todavía una contribución determinante para la agricultura, pero ocupaban el último peldaño de la escala social: pobres, explotados, víctimas de un fuerte racismo. Pero, por casi un siglo, los salesianos no se ocuparon de ellos, sino de una ínfima minoría, constituida por los llamados primitivos o salvajes ¿Por qué? Se pueden intentar algunas explicaciones.

1. El desarrollo de la presencia salesiana en América fue esencialmente urbano. La inmensa mayoría de los salesianos trabajaron y trabajan en las ciudades. Los obispos pedían su presencia para que se ocuparan de la educación y los ayudaran a devolver visibilidad a la iglesia, marginada por los gobiernos liberales.

2. Los indígenas podían ser pobres y marginados pero no corrían el riesgo de condenarse, porque la casi totalidad de ellos estaban bautizados, mientras que los salvajes no conocían a Jesucristo y no pertenecían a la iglesia, puerta de la salvación. 
3. A los salesianos fueron confiados unas jurisdicciones eclesiásticas (Vicariatos, Prefecturas y Prelacías), con la misión específica de convertir los habitantes aun paganos que allí se encontraban. Ese compromiso les vinculó estrechamente con algunas zonas y algunas etnias.

Será solo en las últimas décadas del siglo XX, cuando el Concilio y Medellín proclamaron que la opción preferencial de la iglesia debía ser por los pobres, que los salesianos de varias inspectorías tomaron conciencia que los indígenas de las alturas eran de veras esos pobres y abandonados de los cuales hablaba Don Bosco. Contemporáneamente comenzó el interés por otro fenómeno social de enormes dimensiones: los chicos de la calle.

La labor con los indígenas amazónicos no se detuvo, pero sobrevino una crisis que no se ha superado: el personal va envejeciendo y el relevo no es suficiente.

\section{LA TEOLOGÍA DE LOS MISIONEROS SALESIANOS}

No podría ser sino la típica de su tiempo: salvar almas. La puerta imprescindible de entrada era el bautismo. Lo importante era hacer que la gente se bautizara para asegurarse contra el riesgo de perder definitivamente la visión de Dios. Una interpretación restrictiva de los Padres de los primeros siglos había resumido en una frase que se hizo célebre este tema teológico: "Fuera de la Iglesia no hay salvación". Una imagen bíblica que expresaba claramente este concepto era la del arca de Noé. No existen alternativas: quien entra en ella se salva, quien queda afuera perece. La misionologia aún no aparecía en el horizonte, así que nadie hablaba de la finalidad de la misión como implantación de la Iglesia local y anuncio de los valores del Reino. "Salvar un alma" era visto ya como un premio suficiente para una vida de entrega y un seguro para la salvación eterna del misionero mismo.

Este enfoque iba de la mano con una parábola evangélica aplicada al anuncio apostólico: la del campo y la semilla. Un agricultor prudente, antes de echar el buen trigo, se preocupa de limpiar el campo de toda mala hierba y después vigila para que esta no vuelva a asomar. Aplicación: para que el evangelio sea acogido es indispensable destruir las creencias falsas que un pueblo ha elaborado y después poner mucha atención para que el error no vuelva a invadir el campo. 
En otras palabras: el Evangelio está llamado a sustituir totalmente el pensamiento religioso de un pueblo.

Pero ¿la religión no es el núcleo más íntimo y fuerte de una cultura? Si se la destruye, ¿cuál suerte correrá la cultura?

\section{La antropología de los misioneros}

¿Qué visión tenían de las culturas de los pueblos a quienes eran enviados? La que era común a todo el mundo occidental.

La aplicación de la teoría evolucionista a las ciencias sociales había llevado a la conclusión que, así como sucede con los diferentes organismos presentes en la naturaleza algunas culturas se han desarrollado mucho y otras han quedado en el estado embrionario, como la de los "salvajes" amazónicos. No faltaron quienes opinaban que era inútil gastar tiempo con sus portadores, porque no poseían un cociente de inteligencia que les permitiera progresar. Pero la otra corriente que se impuso fue la del mariscal Cándido Mariano da Silva Rondón, conocido y apreciado en todo el mundo. El estaba convencido que, siendo seres humanos, con una paciente labor educativa, llegarían a "civilizarse".

Su enfoque era el típico del pensamiento liberal y masónico, pero los misioneros lo compartían, añadiendo que era indispensable el anuncio de la religión verdadera.

La antropología, vista como una disciplina digna de ciudadanía entre todas las demás ciencias sociales, recién empezaba a dar sus primeros pasos. Y no se puede ignorar que muchos de los antropólogos culturales de los tiempos iniciales fueron enrolados por las potencias coloniales para que, a través del conocimiento de las dinámicas en las culturas, fueron útiles auxiliares para la administración de sus imperios. Es el caso de Bronislav Malinowski en relación con el imperio británico.

\section{LA PREPARACIÓN PARA IR A LAS MISIONES}

Los salesianos que iban a las misiones recibían la formación estandarizada de todos los demás religiosos: ciertas bases filosóficas y teológicas, espíritu de piedad, entrenamiento para una vida sobria.... Nada de específico. 
En el lugar del trabajo cada uno buscó moverse guiado por la experiencia adquirida en su tierra y por el sentido común. El hecho que pronto se empezó a enviar personal en edad muy joven, facilitó su inserción en la mentalidad, lengua y cultura el país de destino, pero favoreció también la asimilación de los prejuicios locales con respecto a los pueblos "primitivos".

Casi todos los salesianos (y no fueron pocos) que llegaron a realizar investigaciones importantes, y a producir obras muy apreciadas en áreas como la etnografía, la lingüística, la etnohistoria, etc... fueron autodidactas y emprendieron sus iniciativas más movidos por el entusiasmo personal que por el empuje de la Congregación como tal.

Probablemente ha sido preferible que las cosas se dieran así. Si hubieron sido enviados a las universidades para una preparación específica, habían absorbido el espíritu nacionalista propio de la época. Todas las naciones que tenían colonias hicieron lo posible para utilizar a los misioneros para sus propósitos patrióticos e intereses nacionales.

\section{LOS MÉTODOS DE EVANGELIZACIÓN}

Puestas las premisas que lo esencial era que los indígenas llegaron a aceptar el bautismo y que entraron en el proceso de "civilización", los instrumentos para lograrlo se fueron adaptando a las circunstancias.

En la mayoría de las misiones amazónicas el método más utilizado fue el del internado: en Ecuador, en el Rio Negro y en el Alto Orinoco con diferentes etnias. En el Matto Grosso con los Bororo y los Xavante, la praxis fue diferente.

¿Por qué el internado? Los motivos son varios. Se pueden enumerar algunos.

1. Es típico de la tradición salesiana partir de los niños y jóvenes, para convertirlos en cristianos y ciudadanos de bien.

2. Tratándose de pueblos cuyo habitat es muy disperso, resultaba imposible proporcionarles el servicio de la escuela sin agruparlos en la misión.

3. No se puede negar que el ambiente familiar no era visto con ojos positivos. En fin de cuenta se los consideraba "salvajes". Por eso la tendencia a mantener a los niños y niñas alejados del mismo. 
Además de proporcionarles las herramientas para entrar en contacto con la sociedad envolvente, a través del aprendizaje de la lengua, la escritura y ciertas destrezas propias el mundo blanco, la preocupación de los misioneros era la de acostumbrarlos a cierta disciplina y a un ritmo de trabajo que más tarde los ayudara a volverse económicamente autosuficientes.

Este esfuerzo no logró los efectos esperados y hubo un momento en que el sistema del internado fue fuertemente criticado por separar a los niños de sus familias. En el Río Negro de Brasil las críticas fueron particularmente severas y desembocaron en denuncias.

El número de salesianos y salesianas que sacrificó su vida en las misiones amazónicas fue altísimo: centenares de personas. Tal vez ninguna Congregación dio un aporte parecido.

No se puede negar que la entrega personal y la generosidad fueron enormes. Pero resulta también evidente que, de acuerdo a la visión de las cosas que se manejaba entonces, se trató de una actividad marcada por el paternalismo. El indio sí era visto como una persona, pero una persona necesitada de tutelaje y aun no del todo adulta.

\section{ANTROPÓLOGOS Y MISIONEROS SALESIANOS}

Las relaciones variaron de un lugar a otro, pero en general entre los dos gremios existió bastante desconfianza.

Los antropólogos veían a los misioneros como personas un tanto fanáticas, obsesionadas por imponer nuevos códigos morales y por cambiar las costumbres tradicionales. Los misioneros veían en los antropólogos unos estudiosos solo dedicados a investigar la cultura indígena para realizar sus tesis y publicar sus libros, con el fin de ascender académicamente. Una crítica a los salesianos que llegó a ser conocida por el gran público fue la que hizo Claude Lévi Strauss a la labor misional con los Baroro en su célebre obra: "Tristes Tropicos". Para complicar las relaciones se dieron también casos de antropólogos que aprovecharon de mucha información de los misioneros y después no solo la utilizaron sin reconocer las fuentes, sino que en sus obras criticaron sin piedad la labor misionera. 
Pero la situación no fue la misma en todas partes. Por ejemplo, si en el Ecuador en los últimos 50 años las relaciones fueron más que cordiales, en el Rio Negro hubo momentos de fricción muy grande: actitud totalmente cerrada de parte de la misión, ataques públicos y hasta malévolos de los antropólogos.

\section{EL CAMBIO}

En las últimas décadas del siglo XX la orientación del trabajo misionero conoció un cambio radical para el cual coincidieron diferentes factores.

En lo teológico un impulso decisivo vino del Concilio vaticano. Al retomare la afirmación de S. Irineo que Dios está presente en todas las culturas a manera de semilla ( Semina Verbí) se impuso una diferente valoración de las creencias religiosas de los pueblos. El anuncio evangélico no viene a destruir y sustituir sino a iluminar y ayudar a crecer algo ya existente. Los esfuerzos para reorientar la catequesis e inculturar la liturgia fueron enormes, especialmente entre los Xavantes, los Shuar y los Yanomani. Esto implicó una nueva dedicación al estudio de los idiomas y una intensificación de las investigaciones sobre las mitologías. Contemporáneamente se multiplicaron los esfuerzos para traducir la sagrada Escritura a las lenguas locales.

Las publicaciones de las mitologías de los Bororo, Xavante y Shuar alcanzaron dimensiones monumentales.

Cuanto a la antropología desde años venia abriéndose paso la nueva visión, que superaba el darwinismo aplicado las ciencias sociales y proclamaba que no se puede aplicar a las culturas la clasificación de superiores e inferiores; son diferentes, pero todas igualmente legítimas y dignas de consideración.

El documento que sacudió fuertemente el mundo misionero fue la Declaración de los 12 antropólogos reunidos en la isla de Barbados en 1971, que movió fuertes críticas al modus operandi de las misiones.

Unas iniciativas en los Vicariatos de Puerto Ayacucho y Méndez imprimieron una aceleración a la puesta en marcha de la renovación. Mons. Enzo Cecarelli envió 4 salesianos y una Hija de María Auxiliadora al Instituto de Antropología Misionera de Bogotá. Los cinco formaron un equipo que lideró la puesta al día de la pastoral misionera.... La inspectoría de Cuenca (Ecuador) envió también una 
media docena de misioneros a frecuentar un año de misiologia en la universidad Gregoriana. Entre ellos Luis Bolla, Siro Pellizaro, Juan y Domingo Bottasso. Recién había terminado el Concilio y los nuevos fermentos teológicos y antropológicos se advirtieron enseguida.

Después de cierta fase de euforia, lamentablemente sobrevino una pausa y un estancamiento.

El personal, especialmente extranjero, comenzó a envejecer y faltó un recambio adecuado. También el mundo circundante comenzó a cambiar (globalización) y con él la sensibilidad de los indígenas, especialmente jóvenes, hoy mucho más interesados a la modernización que apegados a sus tradiciones.

Si queremos mirar hacia el futuro, preguntándonos cuál es el sentido de nuestra presencia en la Amazonia creo que no podemos prescindir de tener en cuenta algunos datos.

1. Como salesianos somos menos numerosos y se prevé que la situación no va a cambiar.

2. Ya no somos solos, como cuando a un obispo salesiano le encargaron la atención a los indios de tres países. Hoy no solo son numerosos las instituciones religiosas presentes en el area sino que son aun más numerosas las estatales, científicas, las ONG que se ocupan del ambiente y de los pueblos que lo habitan. Quedar aislados es condenarse a la irrelevancia. Es absolutamente indispensable trabajar en red. Tenemos una inmensa riqueza de experiencia que compartir, pero también la posibilidad de acceder a un patrimonio enorme de información .

No se trata solo de buscar el contacto con antropólogos y lingüistas, sino con ambientalistas, economistas, expertos en desarrollo sostenible.

3. Se repite como un mantra que los jóvenes son el futuro de un país. Esto vale también para los pueblos indígenas.

Hoy los jóvenes de todos estos pueblos viven una crisis profunda, pierden interés por sus antiguos patrones culturales pero no se orientan fácilmente ante la multiplicidad de ofertas que les llegan de la modernidad. Como salesianos, exactamente para ser fieles a nuestro carisma, deberíamos convertirnos en expertos en el conocimiento de las actuales orientaciones de la juventud indígena. 
Ya no alcanzamos, como un tiempo a ocuparnos casi totalmente de su escolarización. Deberíamos concentrarnos en formar escuelas de líderes, capaces de orientar a sus comunidades, sin dejarse envolver y utilizar por las politiquerías locales.

\section{Sobre o autor:}

Juan Bottasso Boetti: Doutor em Antropologia- Universidade Politécnica Salesiana (UPS), Quito. Equador. E-mail: juanbottasso@yahoo.com

Recebido em 7 de novembro de 2018

Aprovado para publicação em 12 de novembro de 2018 